\title{
The Relationship between Social Presence and Critical Thinking: Results from Learner Discourse in an Asynchronous Learning Environment
}

\author{
Jamie Costley \\ Kongju National University, \\ Gongju, South Korea
}

costleyiamie@gmail.com

\author{
Christopher Lange \\ Joongbu University, \\ Guemsan, South Korea
}

christopherhlange@gmail.com

\begin{abstract}
Understanding the relationship between social presence and critical thinking is useful for gaining insight into the interaction and discourse of learners online. Further study of how these two presences interact is important because research has shown a wide variety of relationships, both positive and negative, between social presence and critical thinking. The aim of this study is to investigate social presence and critical thinking using discourse analysis in the hope that it will deepen and broaden our understanding of the relationship between these important facets of learner discourse. Using quantitative analysis, an online forum used by students at a national university in Korea $(n=219)$ was analyzed by taking 900 forum posts to determine the levels of social presence and critical thinking in each post. The relationships between social presence and critical thinking were analyzed and the results show that social presence and critical thinking have a negative correlation. This highlights the need for awareness of learner discourse, as an increase in social presence may lead to a decrease in critical thinking and vice versa. The likely cause of this is that learners tend not to change the discourse once the discourse within a particular context has been set.
\end{abstract}

Keywords: CMC, CoI, critical thinking, learning communities, online learning, social presence

\section{Introduction}

Within the context of computer-mediated communication (CMC), the learner typically becomes actively involved with the construction of knowledge through a collaborative process that occurs in an online community. This learner-centered paradigm has been brought about by our current understanding of community and psychology as they relate to learning. As Dewey (1933) notes, learners and the communities they hail

Material published as part of this publication, either on-line or in print, is copyrighted by the Informing Science Institute. Permission to make digital or paper copy of part or all of these works for personal or classroom use is granted without fee provided that the copies are not made or distributed for profit or commercial advantage AND that copies 1) bear this notice in full and 2) give the full citation on the first page. It is permissible to abstract these works so long as credit is given. To copy in all other cases or to republish or to post on a server or to redistribute to lists requires specific permission and payment of a fee. Contact Publisher@,InformingScience.org to request redistribution permission. from cannot be meaningfully separated. An essential component allowing for such cohesion is social interaction, which proceeds learning in most cases (Vygotsky, 1978). Higher levels of interaction lead to greater knowledge development and stronger social ties online, further integrating learners with the communities in which they coexist (Tan, Tripathi, Zuiker \& Seah, 2010). 
Communities of practice develop such coexistence through interaction, as learners share and engage in a constantly negotiated joint enterprise (Lave \& Etienne, 1991). It is noted that learning involves participation in communities of practice, which can be defined by the quality and number of interactions between the participants (Lave \& Etienne, 1991). Therefore, it is evident that these communities of practice reflect the ideas of both Dewey and Vygotsky, as they bring the community and learners together through meaningful interaction, which leads to learning.

Closely related to the community of practice is a model called the Community of Inquiry (CoI). This model was developed for use in an e-learning environment and serves as one of the most widely tested models (Garrison, Anderson, \& Archer, 2000; Lee, 2013). It also offers an understanding of how the pieces of the CoI work together, providing a conceptual tool for understanding CMC as well as a model for the CoI. It consists of three parts: cognitive presence, social presence, and teaching presence. The first element in the model that is core to learning is cognitive presence, which is defined as the extent to which the participants construct meaning through ongoing interaction (Garrison, et al., 2000). Cognitive presence is related to and similar with ideas of critical thinking. In the context of representing a learner outcome, critical thinking is the attainment of a rich and meaningful understanding, through the application of critical inquiry skills and abilities related to domain-specific contents (Garrison, Anderson, \& Archer, 2001). Garrison et al.'s (2001) model can be thought of as a process we can use to describe the various phases learners go through to achieve a level of critical thinking. The second element in the model is social presence. Social presence is the ability of learners to become part of a learning community through purposeful communication. This allows them to show their personal characteristics within the CoI. The third element of the model, teaching presence, consists of instructor behaviors that help facilitate and direct learning within the context of an online learning environment.

Previous research has focused on the relationship between the three presences within the CoI. In particular, the relationship between social presence and cognitive presence has been a source of focus, leading to varied findings. Regardless of the variation of the findings, they give support for the importance of studying the relationship in a broad context. While research conducted by Garrison, Cleveland-Innes, and Fung (2010) has shown that perception of social presence has a significant influence on the perception of cognitive presence, other research, such as that conducted by Nagel and Kotzé (2010), claims that social presence may not actually lead to higher order cognitive presence. The findings by Garrison et al. (2010) are based on student perceptions obtained from survey analysis, which may not represent what is actually taking place within a specific online learning community. Quantifying qualitative data through the analysis of learner discourse may provide a more complete picture of what is actually occurring. The present study uses a critical thinking coding scheme developed by Newman, Webb, and Cochrane (1996) as well as a social presence coding scheme developed by Rourke, Anderson, Garrison, and Archer (1999) in order to analyze the relationship between the two presences. Furthermore, possible causes of the relationship are discussed. Keeping this in mind, the following research questions are presented for this study:

1. What are the levels of social presence and critical thinking within an online forum?

2. What is the relationship between social presence and critical thinking?

3. What are the relationships between the individual indicators of social presence and critical thinking? 


\section{Theoretical Background}

\section{Social Presence}

Sacks, Schegloff, and Jefferson (1974) claim that discourse needs to be able to accommodate a diversified social setting in which people interact in a variety of ways. Ultimately, it is up to the participants who control the discourse through their interactions to ensure this occurs. Van Dijk (2008) reflects this by stating that those who are interactively involved in the discourse define the social setting and what is considered socially appropriate by the participants. Such interaction between participants is used to effectively sustain the discourse within a face-to-face environment. Of equal importance is sustaining this discourse in a CMC environment, where interaction between the participants leads to a level of social presence. Lacking the physical presence of the participants, social presence within an online environment is thought of as the extent to which learners are able to view each other as actual people participating in mediated communication (Gunawardena, 1995). Furthermore, it has been claimed that social presence not only exists within a CMC environment, but that it is actually "cultured" by the participants through interaction, and that interaction becomes social presence only once it is actually realized by the learners (Gunawardena, 1995). Tu and McIssac (2002) also connected social presence with interaction, stating that social presence within an online community leads to more interaction between the participants. Rourke et al. (1999) defined social presence within the CoI framework, claiming that it is the ability of learners to project themselves through not only social means, but through affective means as well. Rourke et al. (1999) describe how social dimensions of interaction can be met within an online community, claiming that learners and instructors tend to use a great deal of text introducing themselves, making jokes and attempting to relate to others within the learning community.

Many researchers such as Gunawardena (1995), Rourke et al. (1999), and Tu (2002) have used varied methods to measure the construct of social presence. Gunawardena's work is based around a set of 17 Likert scale items that measured the degree of social presence learners felt in CMC learning environments. These items asked learners to score where on the scale they felt the learning environment was. For example, student perceptions of how active, passive, stimulating, or dull they found the learning environment created an overall measure of the level to which a learning environment contained social presence. Gunawardena's (1995) scale was further developed in collaboration with Zittle (Gunawardena \& Zittle, 1997) with 14 items that asked participants their level of agreement with statements made about the learning environment. This scale was tested for internal reliability (Alpha $=.88)$, which the first scale was not. Gunawardena and Zittle (1997) claim this scale measures social presence more accurately than Gunawardena's (1995) scale.

In 2002, Tu developed a scale named The Social Presence and Privacy Questionnaire (SPPQ). Five content experts initially developed this survey. In an experiment with 310 learners to test construct validity, factor analysis showed that five features stood out as being important. These features (social context, online communication, interactivity, system privacy, and feelings of privacy) made up the core of measuring social presence. In further work, Tu and McIssac (2002) found that more variables may impact social presence, and that the dimensions of social presence may need to be weighted for more accurate measurement.

Rourke et al. (1999) took an important second step in the measurement of social presence by looking at learner discourse directly, as opposed to using a survey as in Gunawardena (1995), Gunawardena and Zittle (1997), and Tu and McIssac's (2002) research. This measurement of social presence used the analysis of student discourse in the form of transcripts from an asynchronous online learning class. This was done to understand learner-to-learner interaction. Rourke et 
al.'s (1999) claim is that directly measuring discourse allows researchers to see the degree to which learners project themselves socially and affectively in online learning environments.

It has been suggested that social presence can be measured in a variety of ways. It is generally the case that social presence is measured in the form of a survey at the completion of any particular course or learning block. However, rather than relying on learner perception of social presence levels, discourse analysis using a coding scheme as in Rourke et al. (1999) and in this study gives a richer and more objective description of how students are engaging online.

\section{Critical Thinking}

Dewey (1933) defines critical thinking as a form of reflective thinking that is an active, continual reflection on a belief or form of knowledge including the development of supporting factors and conclusions of that belief or form of knowledge. Dewey's (1933) reflective thinking model explains that the main benefit of critical thinking is that it helps learners develop and deepen the picture of their experiences. For this reason, critical thinking is important at every stage of learning. Critical thinking allows learners to assess the quality of their current knowledge and incoming knowledge; it also allows learners to develop knowledge of their own by combining previously acquired knowledge with new concepts and ideas (Anderson \& Garrison, 1995).

According to Garrison and Archer (2000), the advantage of Dewey's framework of reflective thinking is that most forms of active cognition (critical, abstract, or inference, for example) can be explained by the theory. Garrison and Anderson (2003) point out that the core principle of the model, which moves through imagination, deliberation and action, can be linked easily to most learners' experiences of e-learning. This is even more the case when the e-learning is asynchronous and written. This creates a discourse that is heavily weighted towards reflection, which can be contrasted with most verbal discourses that tend to be spontaneous and lack reflection (Garrison \& Anderson, 2003). Research involving the analysis of discourse has shown the relationship between features of online discourse that make up critical thinking and learning (Pilkington, 2001). Pilkington's analysis allows us to indirectly understand how the process of discussion intersects with processes inside learners' minds. This is evident in that successful exchanges within collaborative discussion often include critical thinking processes displayed by the learners, such as explaining, clarifying, challenging and justifying. This aligns critical thinking with learner processes in order to contribute efficiently to active discussions.

Within the CoI, and for the purposes of this study, critical thinking can be considered somewhat synonymous with cognitive presence (Garrison \& Archer, 2000). Critical thinking can also be modeled in concert with the Practical Inquiry Model. This brings the concept of critical thinking more in line with learning processes as opposed to outcomes. The Practical Inquiry Model has four stages: triggering, exploration, integration, and resolution; these are generated from Dewey's idea of reflective thinking. This model is useful in understanding learning processes online; but as Swan, Garrison and Richardson (2009) point out, the relationship between these events is neither linear nor discrete. This is evident in that the stages are closely related to each other and often require revisiting to move the process in a new direction or obtain new information (Swan et al., 2009). With respect to these stages, thinking of cognitive presence in terms of critical thinking is relevant when looking at them as a learner-initiated process based on reflective thinking. Furthermore, critical thinking is an important part of learner discourse as it relates to the way learners interact and learn online.

\section{Relationship between Social Presence and Critical Thinking}

Within the CoI model, social presence has commonly been viewed as playing a vital role in the support of cognitive presence by not only instigating, but also sustaining and supporting critical 
thinking within a learning community (Lee, 2013). Garrison et al. (2000) make the claim that when high levels of social presence occur, the likelihood of the learners to engage in higher order critical thinking increases. These authors comment further on social presence, claiming that social presence supports cognitive presence in a way that indirectly facilitates critical thinking among the learners (Garrison et al., 2000). This shows that by facilitating critical thinking, social presence is viewed as a means to enhance cognitive presence.

A study conducted by Garrison et al. (2010) looked at the relationships between social presence, cognitive presence, and teaching presence. It was found that not only did the perception of social presence have a significant influence on the perception of cognitive presence, but that social presence acted as a mediating variable between teaching presence and cognitive presence. In this study, 14 different online university courses focusing on various subjects were chosen. A total of 287 participants responded to a survey regarding the levels of CoI presences perceived online. All the courses contained an online conferencing component to promote student interaction. Within the 14 courses, mandatory online participation was required for some, while not required for others. The results showed that the relationship between social and cognitive presence were positive regardless of the varying contexts of the courses. This lends justification for the research of the relationship based on a broad context. Garrison et al.'s (2010) findings were based on survey analysis rather than quantitative content analysis, leaving it up to the students' perceptions rather than an actual analysis of student-provided content.

Research conducted by Kozan and Richardson (2014) used a 34-item CoI framework survey given to 211 graduate students in online courses, which measured the three presences of the study with a five-point scale. The relationships between teaching, social, and cognitive presences were looked at and the results were telling in regards to the role of social presence in online learning. The findings supported Garrison et al.'s (2000) claim that social presence facilitates cognitive presence. More specifically Kozan and Richardson's (2014) results were similar to that of Garrison et al. (2010) in that they showed a strong positive correlation between social presence and cognitive presence, but unlike the Garrison et al.'s (2010) study, social presence was not seen to be a mediating factor between teaching presence and cognitive presence. These results support that the relationship holds over a wide variety of education contexts as the six courses used in the study had varied curricula.

A quantitative content analysis study of 18 online learners recently conducted by Shea, Hayes, Uzuner-Smith, Gozza-Cohen, Vickers, and Bidjerano (2014) emphasized the correlations that teaching presence, social presence, and learning presence have on cognitive presence. The new construct of learning presence was used in this study to account for the attitudes, abilities, and behaviors of the online learners. The online learners in this study were divided into teams, with each team in charge of generating the content and questions for the rest of the students on a weekly basis. This provided a wide contextual setting for the students based on group-led instruction which varied on a week-to-week basis. The results showed positive correlations not only between social presence and the newly identified learning presence, but also between social presence and cognitive presence. Although Shea et al. (2014) introduce learning presence into the CoI framework, the positive relationship found between social presence and cognitive presence is consistent with the views of Garrison et al. (2000) that social presence facilitates cognitive presence.

A study conducted by Lee (2013) also used quantitative content analysis by analyzing coded posts within a CoI. Social and cognitive presences were looked at between two graduate classes of a Korean university. The participants in Group A were taking a Multimedia-Assisted Language Learning (MALL) course, while the participants in Group B were taking a Communicative Language Teaching (CLT) course. There were 369 participants from Group A and 303 participants from Group B. A cognitive presence coding scheme was used that focused on four categories: triggering, exploration, integration, and resolution. The social presence coding scheme focused on 
three categories: affective, interactive, and cohesive. A major difference can be seen between the two groups in respect to the pattern of triggering questions. Of the 41 threads analyzed in Group A, 26 of them were initiated by the students, while all of the questions from Group B were initiated by the teacher. Keeping this variation between the two groups in mind, the findings showed that Group A had higher total social presence density (12.299) than cognitive density (9.653), while Group B had higher cognitive density (11.87) than social density (1.979). Looking at the results of both groups based on levels, there appears to be a significant gap between the levels of each presence. However, Lee (2013) makes the case for a positive correlation not based on the levels of cognitive presence, but based on the quality of cognitive presence. Most of the messages by Group B occurred in the first two phases of the cognitive presence scale (triggering and exploration), while messages written by Group A dominated the last two phases (interaction and resolution), which display higher order cognitive skills. Therefore, a positive correlation was shown between social presence and quality of cognitive presence, meaning that as social presence levels went up, the quality of cognitive presence also went up.

Recent research has taken a different position in regards to the relationship between social presence and cognitive presence. Researchers critical of how social presence has been viewed within a CoI have sought to place it in its proper perspective, claiming that it has often been overemphasized. Annand (2011), for example, suggests that previous studies have inappropriately magnified the effect of social presence on cognitive presence, suggesting that other factors such as individual learner attributes and teaching processes have often been overlooked by researchers as potential contributions to the increase of critical thinking within online communities. Nagel and Kotzé (2010) echo this sentiment, claiming that cognitive presence is possibly shaped by the interaction of other presences, and that social presence may not actually lead to a higher order cognitive presence. Adding support to Annand (2011) and Nagel and Kotzé's (2010) criticism of CoI based research, Akyol and Garrison's (2008) study showed that not only was there no significant correlation between social presence and learning, but also that there was no significant correlation between social presence and cognitive presence. Adding justification for the present study, the results from Akyol and Garrisons's (2008) study were gathered from data that was drawn from various contextual settings, as students were given varying tasks throughout the semester. Initially, the online portion of the course consisted of a discussion modeled by the instructor to show the learners how to facilitate the discussion in an effective way. In the next phase, the students were asked to moderate and facilitate the online discussions on their own.

The results of a 2009 study by Gorsky and Blau also show that there is no significant correlation between the two presences. The authors used quantitative content analysis of the posts of 42 graduate students from two different courses to measure the presences associated with the CoI framework. The results show no correlation from either forum despite the fact that each forum contained differing conditions. The conditions creating the independent variables for the study are level of ratings of two teachers, one held in high esteem and one held in low esteem. Despite these different conditions, social presence outweighed cognitive presence in both of the forums.

More evidence calling the relationship of social presence and cognitive presence into question comes from Shea and Bidjerano's (2009) broad contextual study in which teaching, social, and cognitive presences were measured among more than 5,000 online learners from 30 diverse higher education public institutions. The results are telling in that they show, within this broad context, a low amount of social presence was paired with a high amount of cognitive presence, and that the high levels of cognitive presence were related to the levels of teacher presence. Considering evidence from various studies that puts the relationship between the two presences into question, Annand (2011) sums up the results rather directly by stating that "the recurring suggestion of recent CoI-based empirical research is that social presence is of questionable value in the online higher education learning experience because it does not appear to have an important effect on 
cognitive presence" (p. 49). This contrasting view brings the relationship into question, emphasizing the need for further empirical research to determine how social presence and cognitive presence are related to each other in an online learning environment.

\section{Methods}

\section{Subjects and Context}

The 219 participants for this experiment were all taking a class called English for Teaching and Learning in the Classroom that is focused on preparing the students for the Korean teachers entrance exam (im-yong-gyo-shi) over three semesters in 2013 and 2014. There were a total of 229 students taking these classes and all were asked to participate in this study. One student asked not to participate so her posts were not part of the study. Two students did not post on the forum because of a learning impairment so their work was done offline. Furthermore, 7 other students could not be contacted at the end of the semester to complete the surveys, which would have allowed them to participate in this experiment. The 219 students who took part in this study signed consent forms, and posts made by those users were used for analysis.

Table 1. The participants' majors for the three forums.

\begin{tabular}{lcccc}
\hline Major & Semester one & Semester two & Semester Three & Total \\
\hline English & 37 & 35 & 40 & 112 \\
Special & 6 & 6 & 2 & 14 \\
Business & 1 & 2 & 1 & 4 \\
Pedagogy & 3 & 1 & 2 & 6 \\
Art & 2 & 2 & 4 & 8 \\
Life Skills & 5 & 5 & 5 & 15 \\
Ethics & 1 & 3 & 2 & 6 \\
Early Childhood & 2 & 2 & 2 & 6 \\
Literature* & 1 & 2 & 2 & 5 \\
Social Studies & 2 & 2 & 5 & 9 \\
Calligraphy & 0 & 2 & 0 & 2 \\
Korean & 2 & 2 & 3 & 7 \\
Music & 0 & 0 & 2 & 2 \\
Tourism* & 0 & 1 & 0 & 9 \\
Chemistry & 5 & 2 & 2 & 4 \\
History & 2 & 1 & 1 & 5 \\
Earth Science & 1 & 1 & 3 & 2 \\
Economics* & 0 & 1 & 0 & 219 \\
Geography & 0 & 1 & 1 & 77 \\
Total & 70 & 72 & 2 & \\
\hline
\end{tabular}

All majors were part of the college of education except those marked with an *

The posts generated on the online forum were part of a blended learning environment, with the online posting meant to support and further develop the students' offline discourse and writing skills. This was done in the hope that this would develop their ability to generate a meaningful understanding of issues pertaining to class management and delivering instruction. The forum was closed and only students participating in the above mentioned classes participated in it. Offline course activities included lectures, group work, and presentations. The online component of the class was mandatory and worth $25 \%$ of the students' final grade. The online component of the 
course was the students' use of an asynchronous message board where they could post their ideas and respond to others' ideas related to the course materials. The major breakdown for the classes can be seen in Table 1. This class was for students majoring or double majoring in English Education and is therefore dominated by English Education majors, and the majority of the participants are female.

The online activities that were a part of these classes were many and varied. However, they can be summed up into 3 main categories: 1) Free discussion on issues related to the classes. These included advice and support given and received to and from each learner regarding class contents; 2) Discussion focused on specific topics related to the class contents, e.g., debates about the merits of a particular classroom strategy; 3) Specific tasks given to the learners based on the requirements of the class. Examples of this could be posting lesson plans and reviewing other members' lesson plans in preparation for their teaching practicum. The purpose of this study was to give a broad based understanding of the relationship between critical thinking and social presence. For this reason, individual learning tasks were not differentiated so as to look at the phenomena in a natural and expansive way.

\section{Research Procedures}

In the learning environments studied in this research, there were more than nine thousand posts and nearly two thousand threads. It was necessary to reduce the data set to be coded. For this reason, 900 posts were randomly selected to be analyzed for levels of critical thinking and social presence. The sample was generated by randomly selecting a thread within the forum, then randomly selecting a post in that thread. Sampling was done at the level of the thread, and then within the thread posts were selected for analysis. The reason for this was that while analysis was going to be conducted at the level of the post, for each individual post, context (the posts around it) would be required for the coder to make correct coding choices. The procedure for coding the posts follows a structure laid out more clearly in Costley and Han (2013) in which the data goes through an 8 step process. In this paper, this process can be laid out as shown in Table 2:

The coding scheme used for measuring critical thinking in this paper is based on Newman et al.'s (1996) coding scheme for assessing the levels of critical thinking in online environments. This coding scheme is based on the work of Garrison's (1991) five stages of critical thinking and Henri's (1992) framework of cognitive skills. Newman et al. (1996) describe 10 categories of critical thinking: relevance, importance, novelty, outside knowledge, ambiguities, linking ideas, justification, critical assessment, practical utility, and width of understanding. Each of the varied codes can be designated by a (+) or a (-) symbol. This represents whether or not the statement enriches $(+)$ or detracts from (-) the creation of a discourse rich in critical thinking (see Appendix A). Costley and Han (2013) used the same measure on a partial section of the data in previous research. However this paper will use a modification of the above critical-thinking coding scheme. The reason for this is the ratio between 1 and -1 created by Newman et al.'s (1996) coding system is difficult to connect with the outputs of Rourke et al.'s (1999) coding scheme, which is a scale from 0 to 9. For this reason, this research breaks from Newman et al.'s method in that the resulting data would be in the form of a number of events to represent critical thinking as opposed to a ratio. This was done so that it was more in line with the measurements used for social presence, which made the resulting analysis easier and more useful. 
Table 2. The implementation of Costley and Han's (2013) coding procedure in this study

\begin{tabular}{|c|c|c|}
\hline & Coding step & Summary of the steps used in this study \\
\hline 1 & The sample is chosen & $\begin{array}{l}\text { The sampled posts were accumulated in three steps: 1) A } \\
\text { thread was randomly selected, 2) A random number of posts } \\
\text { were selected from that thread, and 3) Steps one and two } \\
\text { were repeated until the } 900 \text { posts used in this study were } \\
\text { accumulated. }\end{array}$ \\
\hline 2 & The unit size decided & The unit size for this study was the post. \\
\hline 3 & The coding scheme is chosen & $\begin{array}{l}\text { The coding schemes used for this study were Newman et } \\
\text { al.'s (1996) scheme for measuring critical thinking and } \\
\text { Rourke et al.'s (1999) scheme for measuring social pres- } \\
\text { ence. }\end{array}$ \\
\hline 4 & $\begin{array}{l}\text { The method of implementing the cod- } \\
\text { ing scheme is chosen }\end{array}$ & $\begin{array}{l}\text { Inter-rater reliability was established, then the posts were } \\
\text { coded, then recoded. }\end{array}$ \\
\hline 5 & $\begin{array}{l}\text { Representing the data in a form it can } \\
\text { be analyzed }\end{array}$ & $\begin{array}{l}\text { The individual codes were summed, giving each post a crit- } \\
\text { ical thinking and social presence "score". }\end{array}$ \\
\hline 6 & Analyzing the data & $\begin{array}{l}\text { The mean levels of social presence and critical thinking } \\
\text { were looked at, and then the correlation between the two } \\
\text { was measured. }\end{array}$ \\
\hline 7 & Interpreting the analysis & $\begin{array}{l}\text { The results were interpreted as showing there was a nega- } \\
\text { tive relationship between social presence and critical think- } \\
\text { ing. }\end{array}$ \\
\hline 8 & Repeating the process for clarity & $\begin{array}{l}\text { Consideration was given to re-coding, however, this was } \\
\text { not done as the results were clear and unambiguous. }\end{array}$ \\
\hline
\end{tabular}

Social presence was measured using a scheme from Rourke et al.'s (1999) “Assessing Social Presence in Asynchronous Text-Based Computer Conferencing". This paper lays out three categories that form the basis of social presence: affective, interactive and cohesive. There are 9 indicators used in this study to generate these three categories: expression of emotions, use of humor, self-disclosure, referring explicitly to others' messages, asking questions, complimenting and expressing appreciation, expressing agreement, addressing or referring to the group using inclusive pronouns, and phatics or salutations (see Appendix B).

The indicators were then used to generate a social presence and critical thinking "score" for each post. An example of a post with the codes included can be seen below with critical thinking codes contained in curly brackets \{\} and the social presence codes contained within square brackets []. The post below contains 4 examples of critical thinking and 1 example of social presence. Therefore the post below would have a social presence score of 1 and a critical thinking score of 4 .

I think teaching is very valuable. Because teaching has strong power to change students. \{Linking Ideas\} When $i$ was a high school student, my grade was good, but i didn't have any dream and $i$ never thought about my future. [Self disclosure] [Experience related to topic\} At that time, my homeroom teacher said, "You are very special.". He taught me how important I am. Also he taught me about importance of dreams. After I heard that, I knew importance of dream and how important I am. \{Justification\} \{Persuasion\} Since then, $i$ want to become a teacher. So I try to study hard to become a teacher. Sometimes, a teacher's advice changes a student's whole life. So teaching has strong power. Like this case, I think teaching has strong power, so i think teaching is very valuable.

Two raters, the main author and one other university professor experienced with online learning coded the data. Initially, the indicators for each construct were discussed, and then ten posts were coded together with discussion about each post. Once that initial stage of discussion was complete, 90 posts were coded by both raters to examine the level of inter-rater reliability. The result- 
ing Cohen's kappas were 0.91 for social presence and 0.86 for critical thinking. Both of these values were considered acceptable and the full set of 900 posts were split in half and coded.

After the initial coding, to further check the reliability of the coding scheme, two more coders checked the already coded samples. This meant that each post was initially coded, and each post was subsequently reread, with the codes included, by two more separate coders. There was a high degree of rater agreement from the checked codes with a Cohen's kappa of 0.96 for social presence and 0.92 for critical thinking.

Internal reliability was also measured with the social presence construct having a Cronbach's alpha of .78. The internal reliability of the critical thinking construct was slightly lower with a Cronbach's alpha value of .75. Both of these values are considered acceptable in research of this kind (Streiner, 2003) and the constructs of critical thinking and social presence were considered reliable enough for analysis.

\section{Results}

The overall levels of social presence and critical thinking were dissimilar in that the average level of critical thinking per post was 3.66, while the average level of social presence per post was 1.99 (see Table 3). As can be seen in Table 3, the mean value of critical thinking is much higher than that of social presence. Although this does not show a correlation between social presence and critical thinking, it does show that the forum posts used in this study showed higher levels of critical thinking than that of social presence. Note that the analysis was at the level of the post, not the learner for the following results.

Table 3. Mean levels of critical thinking and social presence per post

\begin{tabular}{lccccc}
\hline & N & Minimum & Maximum & Mean & Std. Deviation \\
\hline Social presence & 900 & 0 & 9 & 1.99 & 2.168 \\
Critical thinking & 900 & 0 & 9 & 3.66 & 2.134 \\
\hline
\end{tabular}

Table 4. The frequency of occurrence of the particular codes making up social presence

\begin{tabular}{lcc}
\hline & Posts containing the code & $\begin{array}{c}\text { Percentage of posts con- } \\
\text { taining the code }\end{array}$ \\
\hline Expressing Agreement (interactive) & 375 & $42 \%$ \\
Expressing Emotion (affective) & 370 & $41 \%$ \\
Complimenting (interactive) & 244 & $27 \%$ \\
Self-disclosure (affective) & 219 & $24 \%$ \\
Asking questions (interactive) & 156 & $17 \%$ \\
Phatics (cohesive) & 141 & $16 \%$ \\
Referring to others' messages (interactive) & 129 & $14 \%$ \\
Using inclusive pronouns (cohesive) & 82 & $9 \%$ \\
Using humor (affective) & 78 & $9 \%$ \\
\hline
\end{tabular}

Furthermore, within each of the measures used for social presence, variation occurred in regards to how much each code contributed to the constructs. This can be seen in Table 4, which describes how many times the codes appeared. It is evident that posts containing the interactive indicators of social presence (referring to others' messages, asking questions, complimenting, and expressing agreement) were most abundant, comprising a total of 904 codes. This was followed by the affective indicators of social presence (expressing emotion, using humor, and self- 
disclosure), which made up a total of 667 codes. Cohesive indicators of social presence (using inclusive pronouns and phatics) were the least abundant, making up only 223 total codes. These numbers indicate that within this study, the participants relied significantly more on interactive and affective aspects of social presence and very little on cohesive aspects.

Also, in the case of critical thinking there was a degree of variation in the occurrence of each code. This can be seen in Table 5. Relevance and importance topped the list with over 300 posts containing each code respectively. These two indicators serve as outliers, distancing themselves from next closest indicator (complimenting) by over 100 codes. The bottom two indicators (width of understanding and clearing up ambiguities) appear in less than 100 codes respectively, showing the significant difference in the amount of codes containing those indicators compared to the amount of codes containing relevance and importance. This indicates that students relied more heavily on making relevant statements as well as important points and issues when compared to the other critical thinking indicators.

Table 5. The frequency of occurrence of the particular codes making up critical thinking

\begin{tabular}{lcc}
\hline & $\begin{array}{c}\text { Posts containing the code } \\
\text { Rercentage of posts containing the } \\
\text { code }\end{array}$ & $\begin{array}{c}\text { Pevance } \\
\text { Importance }\end{array}$ \\
Linking ideas & 764 & $85 \%$ \\
Practical utility & 732 & $81 \%$ \\
New information & 401 & $45 \%$ \\
Justification & 349 & $39 \%$ \\
Outside knowledge & 345 & $38 \%$ \\
Critical assessment & 339 & $38 \%$ \\
Width of understanding & 267 & $30 \%$ \\
Clearing up ambiguities & 185 & $21 \%$ \\
\hline
\end{tabular}

To answer the main research question of this paper, Pearson and Spearman correlation coefficients were used. Both coefficients found a negative relationship between social presence and critical thinking (Pearson $r$ value $=-.22$, Spearman's rho $=-.24$ ). The correlations were significant at the .01 level ( $\mathrm{sig}=2$-tailed). The plotted-out relationships can be seen in Figure 1.

To further investigate the relationship between social presence and critical thinking, the individual codes that make up both social presence and critical thinking were compared to one another. Unsurprisingly, considering the negative correlation at the level of the construct, most of the individual codes had negative correlations with each other. Among the 90 total comparisons between the critical thinking and social presence indicators, 49 (more than half) of them had a negative correlation. Of those 49 comparisons, 36 of them were significant $(p<.05)$, making an even stronger case for the negative correlation. 


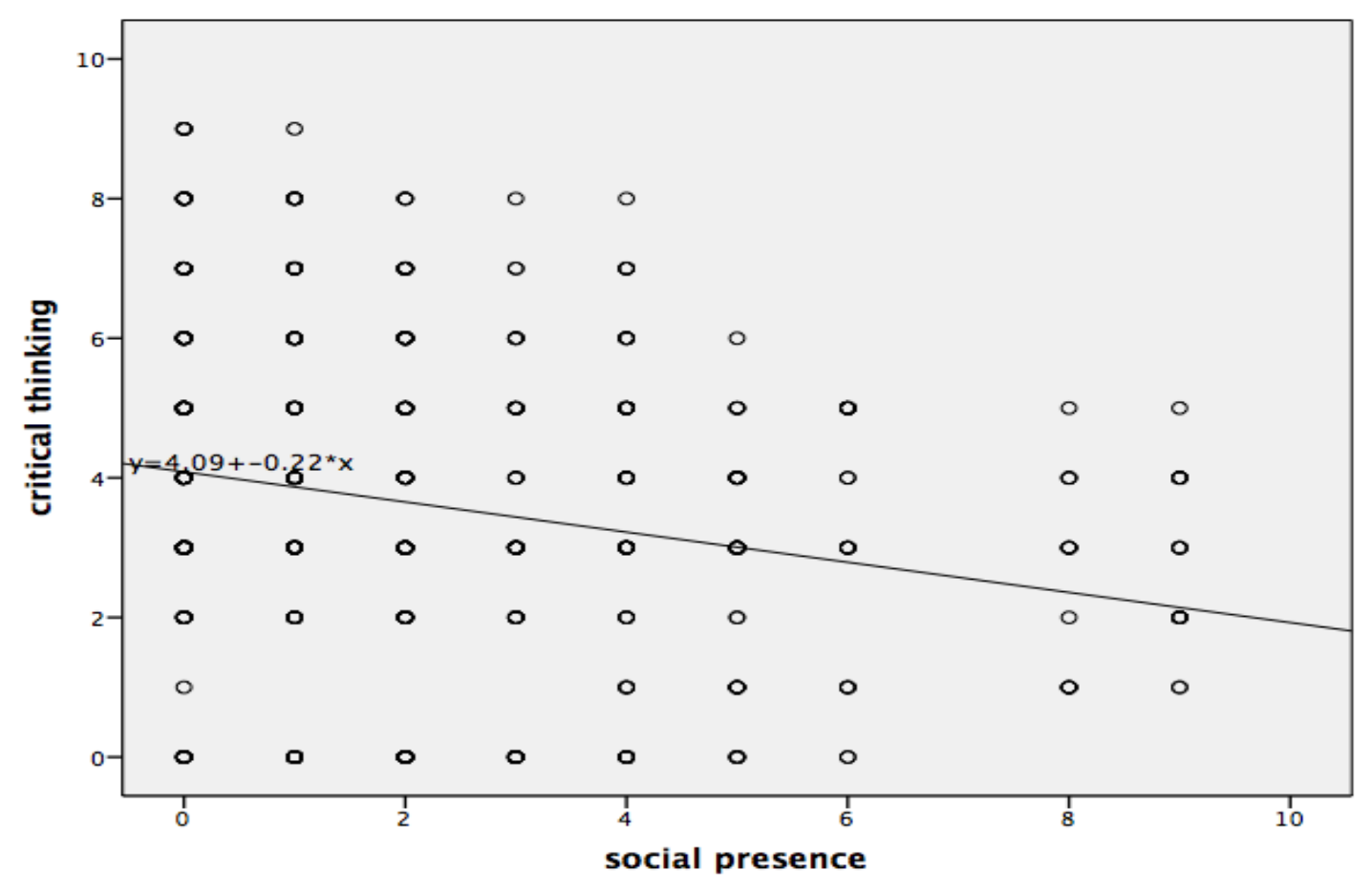

Figure 1. Relationship between social presence and critical thinking

(darker dots represent more posts within that critical thinking and social presence range).

When comparing each critical thinking indicator with all of the social presence indicators, some interesting observations can be made. The two most consistent critical thinking indicators in regards to negative correlations with the social presence indicators are clearing up ambiguities and justification, both of which had a negative correlation with every social presence indicator. Furthermore, all but two of the comparisons with clearing up ambiguities and all but one comparison with justification were significant $(\mathrm{p}<.05)$. Other fairly consistent negative correlations were shown with importance, new information, and width of understanding. When compared with the social presence indicators, new information and importance showed negative correlations with all but three of the social presence indicators, while width of understanding showed negative correlation with all but two of the social presence indicators. An additional noteworthy, and perhaps somewhat surprising point, is the fact that there were no negative correlations found when comparing relevance and outside knowledge with any of the social presence indicators.

When comparing each social presence indicator with all of the critical thinking indicators, additional observations become noteworthy. The most consistent social presence indicators in terms of negative correlation with the critical thinking indicators were disclosure and compliments, each showing that all but two comparisons contained a negative correlation with the critical thinking indicators. Additionally, all of the negative correlations with the disclosure indicator and all but two of the negative correlations with the compliment indicator were significant $(\mathrm{p}<.05)$. The questions indicator proved to be fairly consistent in regards to negative correlation as well. All but three of the comparisons between questions and the critical thinking indicators proved to have negative correlations, with five of the six correlations being statistically significant $(p<.05)$. The social presence indicator that showed the least amount of negative correlation when compared to the critical thinking indicators was agreement, which only showed two negative correlations (see Table 6). 
Table 6. Correlation coefficients for the individual codes within social presence and critical thinking

\begin{tabular}{|c|c|c|c|c|c|c|c|c|c|}
\hline & Humor & $\begin{array}{l}\text { Dis- } \\
\text { close }\end{array}$ & $\begin{array}{l}\text { Compli- } \\
\text { ment }\end{array}$ & $\begin{array}{l}\text { Inclu- } \\
\text { sive }\end{array}$ & Reference & Agree & Emotion & Question & Phatic \\
\hline Importance & $-.08 *$ & $-.17 * *$ & $-.11 * *$ & $-.10 * *$ & -0.04 & -0.05 & $-.08 *$ & $-.07 *$ & -0.06 \\
\hline Relevance & 0.04 & -0.04 & -0.01 & -0.01 & 0.00 & -0.05 & -0.01 & 0.01 & 0.00 \\
\hline $\begin{array}{l}\text { Clearing up } \\
\text { ambiguities }\end{array}$ & $-.13 * *$ & $-.17 * *$ & $-.14 * *$ & $-.11 * *$ & $-.07 *$ & $-.07 *$ & $-.16 * *$ & $-.17 * *$ & $-.13 * *$ \\
\hline $\begin{array}{l}\text { Critical } \\
\text { assessment }\end{array}$ & $-.07 *$ & $-.10 * *$ & $-.12 * *$ & -0.03 & -0.04 & 0.01 & -0.02 & $-.07 *$ & -0.05 \\
\hline Justification & $-.13 * *$ & $-.16 * *$ & $-.15 * *$ & $-.14 * *$ & $-.10 * *$ & $-.08 *$ & $-.14 * *$ & $-.10 * *$ & $-.11 * *$ \\
\hline $\begin{array}{l}\text { Linking ide- } \\
\text { as }\end{array}$ & -0.03 & $.12 * *$ & $-.08 *$ & -0.06 & -0.05 & -0.04 & -0.06 & $-.09 * *$ & -0.05 \\
\hline $\begin{array}{l}\text { New infor- } \\
\text { mation }\end{array}$ & $-.07 *$ & $-.12 * *$ & $-.11 * *$ & $-.11 * *$ & $-.11 * *$ & -0.04 & -0.06 & -0.07 & $-.11 * *$ \\
\hline $\begin{array}{l}\text { Outside } \\
\text { knowledge }\end{array}$ & -0.03 & -0.03 & 0.00 & -0.06 & -0.04 & 0.02 & 0.04 & -0.05 & -0.05 \\
\hline $\begin{array}{l}\text { Practical } \\
\text { utility }\end{array}$ & -0.05 & $-.14 * *$ & $-.10 * *$ & -0.06 & -0.06 & -0.03 & $-.15 * *$ & $-.11 * *$ & $-.14 * *$ \\
\hline $\begin{array}{l}\text { Width of } \\
\text { understand- } \\
\text { ing }\end{array}$ & $-.09 * *$ & $-.12 * *$ & $-.08 *$ & $-.08 *$ & $-.09 * *$ & -0.02 & -0.05 & $-.13 * *$ & $-.08 *$ \\
\hline
\end{tabular}

\section{Discussion}

The results in this study show that there was a negative relationship between social presence and critical thinking. The Pearson's $r$ value between social presence and critical thinking was -22 . This shows that social presence and critical thinking are in tension with one another. As levels of one presence increase, the levels of the other decrease and vice versa. This idea has been looked at and considered by many researchers. However, this study is the first to operationalize and find empirical evidence from learner discourse of this negative correlation. This quote sums up the tension that exists between social presence and critical thinking:

Although we postulate that fairly high levels of social presence are necessary to support the development of deep and meaningful learning, we expect that there is an optimal level above which too much social presence may be detrimental to learning. Discourse in a community of inquiry is not equivalent to social interaction over the garden fence or the bar at a neighborhood pub. Our exploratory study does not indicate if the levels of social presence that we have measured are sufficient, optimal, or even so large as to be detrimental to learning. (Rourke et al., 1999, p. 61)

Although Rourke et al. (1999) discuss the possible dangers of too much social presence, this study magnifies those dangers by providing empirical evidence that social presence can be detrimental to critical thinking and vice versa. The empirical aspects of Rourke et al.'s (1999) research focused on testing the reliability of a specific method to measure social presence, not the relationship between social presence and other aspects of learning. Nonetheless, Rourke et al.'s (1999) cause for concern that too much social presence may actually be detrimental to learning is in line 
with other research that claims social presence may not lead to cognitive presence. Most notably, Annand (2011) presents his case that social presence has no meaningful impact on cognitive presence and supports his claim with previously conducted research. While researchers like Nagal and Kotzé (2010) also make this claim, empirical research conducted by Gorsky and Blau (2009) and Shea and Bidjerano (2009) show that there is no positive relationship between social presence and critical thinking. However, the current study not only found that there is no positive relationship between the two, but that there was, in fact, a negative relationship. This appears to be a significant development leading one to question the cause of this phenomenon.

One explanation for the negative correlation observed between social presence and critical thinking in this experiment can be given by an understanding of the relationship between text and context in the CoI. Van Dijk $(2008,2009)$ explains that the relationship between discourse, whether spoken or text based, and those who are involved in the discourse is mediated by context. The author goes on to explain that context models, or the mental models of those involved in the discourse, shape the way in which the discourse plays out. A further claim is made that these context models ensure that the participants alter their discourse to make sure it is socially appropriate within a given environment (Van Dijk, 2009). Furthermore, people involved in discourse use these context models to keep within the current framework of the discourse, including content and style. In other words, when people are involved in discourse, they tend to use the same style of text or talk that is currently represented by the discourse in which they are participating. Van Dijk (2008) explains that learners, through the use of context models, organize their schema based on fundamental categories, with one category being ongoing social action. Thus the style of the discourse is typically dictated along a continuous, unchanging path based on what the people participating in the discourse believe is socially appropriate to remain on that path.

These same rules can be applied to the discourse that occurs in a CoI. The negative correlation between social presence and critical thinking could be explained by claiming that those involved in discourse follow the same path of the discourse throughout their communicative action. This is because they are unwilling to alter their style because it may be viewed as socially inappropriate (Van Dijk, 2008, 2009). If a student is participating in a discourse that appears heavily influenced by critical thinking, that student will most likely continue along that path throughout his or her individual post, and it seems rather unlikely that he or she would alter the discussion by starting to focus on social presence midway through the post. Using context models, students get a sense of what direction the discourse is going and tend to continue in that direction; therefore preventing them from using high levels of social presence during a post which they feel should be reflective of critical thinking and vice versa.

Further illustration of this point occurs with a deeper analysis of the individual indicators of social presence and critical thinking. For example, the social presence indicator use of humor is negatively correlated with the critical thinking indicators importance and width of understanding. These two critical thinking indicators involve discussing important points/issues and widening a discussion by placing problems within a larger perspective (Rourke et al., 1999). The use of humor such as teasing or sarcasm might very well disrupt this critical thinking discourse and go against what people involved in the discourse feel is socially appropriate (Van Dijk, 2008, 2009). The same holds true when observing the negative correlation between the social presence indicator phatics with the critical thinking indicator clearing up ambiguities for example. Using communication that serves a purely social function as Rourke et al. (1999) put it, would potentially be disruptive to communication focused on clearing up ambiguous statements within a post focused on critical thinking. For example, it seems rather unlikely that a participant would suddenly take a turn to discuss the weather when attempts are being made to clarify statements within a critical thinking discourse. Therefore, it is possible that the participants in this study validated Van Dijk's $(2008,2009)$ claims involving how people generally tend to behave within a specific discourse. 
These views on discourse analysis can contribute to an understanding of the negative correlation between social presence and critical thinking found in this study. In light of this, it is important to note that this research is meant to look at the relationship between social presence and critical thinking in a broad context. Providing justification for this, previous studies (Akyol \& Garrison, 2008; Garrison et al., 2010; Gorsky \& Blau, 2009; Kozan \& Richardson, 2014; Lee, 2013; Shea \& Bidjerano, 2009; Shea, et al., 2014) have also explained the relationship in a broad context. The findings of this study, therefore, can be beneficial to instructors as a general way of looking at the relationship, regardless of context. It is apparent from the results of this study that there is tension between social presence and critical thinking. In light of this discovery, instructors need to be aware of this tension so they can design instruction based on pre-determined desired discourse types.

\section{Conclusion}

This study used quantitative content analysis of an online forum to measure the levels of social presence and critical thinking, the relationship between social presence and critical thinking within a broad context, and the relationships between the indicators of social presence and critical thinking. The results showed that the levels of critical thinking (3.66) were higher than the levels of social presence (1.99). Also, it was found that there was a negative relationship between social presence and critical thinking (Pearson $r$ value $=-.22$, Spearman's rho $=-.24$ ). Additionally, the relationships between the individual indicators of the two presences were measured and more than half of the comparisons between the indicators (49 of the 90 total) showed a negative correlation. A total of 36 of those comparisons were significant $(\mathrm{p}<.05)$. The results indicate that the promotion of one presence may be detrimental to the other. This leads to the conclusion that the goals of any learning environment must be taken into consideration when designing a forum for learners to use. Modification may lead to changes in outputs; therefore instructors must focus on what design decisions will best suit the students under their charge. The tension between social presence and critical thinking, as well as the tension between their indicators, further demonstrates the importance of care when designing and delivering online instruction.

This study contributes to previous research about the relationship between social presence and critical thinking. Through empirical observation of the negative relationship between the two presences, this study builds on Rourke et al.'s (1999) discussion about the possible dangers of using too much social presence, however there are some limitations. This study does not discuss the tipping point of when too much social presence is detrimental to critical thinking and vice versa. This study was meant to provide a general overview of the negative relationship in hopes that instructors can not only be aware of it, but also adjust accordingly. Future researchers interested in the causes and prevention of the tipping point should use a qualitative approach to look at the relationship between social presence and critical thinking. This should be done to provide a descriptive account of when the imbalance created by one presence becomes detrimental to the other. With that being said, future research should look into this imbalance and attempt to find out how to avoid the tipping point through specific contextual education situations, for example, designing tasks that minimize the negative relationship. Although this study looked at the relationship in a broad context, it would be useful for future studies to measure the relationship based on specific contexts. Certain tasks or activities may be beneficial in keeping the balance between social presence and critical thinking. In this study, for example, differing activities included free discussion, discussion focused on specific topics related to class content, and discussions based on the requirements of the class. It could very well be the case that levels of social presence and critical thinking vary based on these differing activities. Although this study did not differentiate between these tasks in order to give a broad based understanding of the relationship, being aware of contextual situations which promote more of a balance between social presence and critical thinking would be helpful for instructors who wish to maintain the balance between the two. 
Furthermore, using specific contexts to examine differences between posts, rather than within posts would be helpful to see why "turns are valued, sought, or avoided" by participants (Sacks et al., 1974). This could possibly contribute to an imbalance between social presence and critical thinking. This can be explained through turn-taking and how participants keep within the context of the discourse by taking or avoiding turns in the discussion based on the context of previous turns taken by other participants. Although this study did not examine this aspect of the relationship, the results are useful in that they provide a general overview of the relationship between social presence and critical thinking so that future research can take the next step by looking into more specific aspects of the relationship.

\section{References}

Anderson, T. D., \& Garrison, D. R. (1995). Critical thinking in distance education: Developing critical communities in an audio teleconference context. Higher Education, 29(2), 183-199.

Annand, D. (2011). Social presence within the community of inquiry framework. The International Review of Research in Open and Distributed Learning, 12(5), 40-56.

Akyol, Z., \& Garrison, D. R. (2008). The development of a community of inquiry over time in an online course: Understanding the progression and integration of social, cognitive and teaching presence. Journal of Asynchronous Learning Networks, 12(3), 3-22.

Costley, J., \& Han, S. (2013). Applying quantification of qualitative verbal data to asynchronous written discourse. Creative Education, 4, 1-8.

Dewey, J. (1933) How we think (rev. ed.), Boston: Houghton Mifflin.

Garrison, D. R. (1991). Critical thinking and adult education: A conceptual model for developing critical thinking in adult learners. International Journal of Lifelong Education, 10(4), 287-303.

Garrison, D. R. (2009). Communities of inquiry in online learning. In P. L. Rogers et al. (Eds.), Encyclopedia of distance learning ( $2^{\text {nd }}$ ed., pp. 352-355). Hershey, PA: IGI Global.

Garrison, D. R., \& Anderson, T. (2003). E-learning in the $21^{\text {st }}$ century: A framework for research and practice. London: Routledge/Falmer.

Garrison, D. R., Anderson, T., \& Archer, W. (2000). Critical inquiry in a text-based environment: Computer conferencing in higher education. The Internet and Higher Education, 2(2), 87-105.

Garrison, D. R., Anderson, T., \& Archer, W. (2001). Critical thinking, cognitive presence, and computer conferencing in distance education. American Journal of Distance Education, 15(1), 7-23.

Garrison, D. R., \& Archer, W. (2000). A transactional perspective on teaching and learning: A framework for adult and higher education. Oxford: Pergamon.

Garrison, D. R., Cleveland-Innes, M., \& Fung, T. S. (2010). Exploring causal relationships among teaching, cognitive and social presence: Student perceptions of the community of inquiry framework. The Internet and Higher Education, 13(1), 31-36.

Gorsky, P., \& Blau, I. (2009). Online teaching effectiveness: A tale of two instructors. The International Review of Research in Open and Distributed Learning, 10(3).

Gunawardena, C. N. (1995). Social presence theory and implications for interaction and collaborative learning in computer conferences. International Journal of Educational Telecommunications, 1(2), 147-166.

Gunawardena, C. N., \& Zittle, F. J. (1997). Social presence as a predictor of satisfaction within a computermediated conferencing environment. The American Journal of Distance Education, 11(3), 8-26.

Henri, F. (1992). Computer conferencing and content analysis. In A.R. Kaye (Ed), Collaborative learning through computer conferencing: The Najaden papers, 117-136. 
Kozan, K., \& Richardson, J. C. (2014). Interrelationships between and among social, teaching, and cognitive presence. The Internet and Higher Education, 21, 68-73.

Lave, J., \& Etienne W. (1991). Situated learning: Legitimate peripheral participation. Cambridge: University of Cambridge Press.

Lee, S. M. (2013). The relationships between higher order thinking skills, cognitive density, and social presence in online learning. The Internet and Higher Education, 21, 41-52.

Nagel, L., \& Kotzé, T. G. (2010). Supersizing e-learning: What a CoI survey reveals about teaching presence in a large online class. The Internet and Higher Education, 13(1), 45-51.

Newman, D. R., Webb, B., \& Cochrane, C. (1996). A content analysis method to measure critical thinking in face to face and online supported group work. Retrieved July 2nd 2013, from http://www.qub.ac.uk/mgt/papers/methods/contpap.html

Pilkington, R. (2001). Analysing educational dialogue interaction: Towards models that support learning. International Journal of Artificial Intelligence in Education 12, 1-7.

Rourke, L., Anderson, T., Garrison, D., \& Archer, W. (1999). Assessing social presence in asynchronous text-based computer conferencing. International Journal of E-learning and Education, 14(2), 50-71.

Sacks, H., Schegloff, E. A., \& Jefferson, G. (1974). A simplest systematics for the organization of turntaking for conversation. Language, 696-735.

Shea, P., \& Bidjerano, T. (2009). Cognitive presence and online learner engagement: A cluster analysis of the community of inquiry framework. Journal of Computing in Higher Education, 21(3), 199-217.

Shea, P., Hayes, S., Uzuner-Smith, S., Gozza-Cohen, M., Vickers, J., \& Bidjerano, T. (2014). Reconceptualizing the community of inquiry framework: An exploratory analysis. The Internet and Higher Education, 23, 9-17.

Streiner, D. L. (2003). Starting at the beginning: An introduction to coefficient alpha and internal consistency. Journal of Personality Assessment, 80, 99-103.

Swan, K., Garrison, R., \& Richardson, J. C. (2009). A constructivist approach to online learning: The Community of Inquiry framework. In C. Payne (Ed.), Information technology and constructivism in higher education: Progressive learning frameworks (pp. 43-57). Hershey, PA: IGI Global.

Tan, M., Tripathi, N., Zuiker, S. J. \& Seah, H. S. (2010). Building an online collaborative platform to advance creativity. Paper presented at the 4th IEEE International Conference on Digital Ecosystems and Technologies.

$\mathrm{Tu}, \mathrm{C}$. H. (2002). The measurement of social presence in an online learning environment. International Journal of E-Learning, 1(2), 34-45.

Tu, C. H., \& McIsaac, M. (2002). The relationship of social presence and interaction in online classes. The American Journal of Distance Education, 16(3), 131-150.

Van Dijk, T. A. (2008). Discourse and context: A sociocognitive approach. Cambridge.

Van Dijk, T. A. (2009). Society and discourse: How social contexts influence text and talk. Cambridge University Press.

Vygotsky, L. S. (1978). Mind in society. Cambridge, MA: Harvard University Press. 


\section{Appendix A. Newman, Webb, and Cochrane's (1996) Coding Schema}

\begin{tabular}{|c|c|}
\hline Category & Positive Indicator \\
\hline $\mathrm{R} \pm$ Relevance & $\mathrm{R}+$ Relevant statements \\
\hline I \pm Importance & I+ Important points/issues \\
\hline N+- Novelty. New info, ideas, & $\mathrm{NP}+$ New problem-related information \\
\hline \multirow[t]{5}{*}{ Solutions } & $\mathrm{NI}+$ New ideas for discussion \\
\hline & NS+ New solutions to problems \\
\hline & NQ+ Welcoming new ideas \\
\hline & $\mathrm{NL}+$ learner (student) brings \\
\hline & new things in \\
\hline \multirow{7}{*}{$\begin{array}{l}\mathrm{O} \pm \text { Bringing outside knowledge or } \\
\text { experience to bear on problem }\end{array}$} & $\mathrm{OE}+$ Drawing on personal experience \\
\hline & $\mathrm{OC}+$ Refer to course material \\
\hline & $\mathrm{OM}+$ Use relevant outside material \\
\hline & $\mathrm{OK}+$ Evidence of using previous \\
\hline & Knowledge \\
\hline & $\mathrm{OP}+$ Course related problems brought in \\
\hline & OQ+ Welcoming outside knowledge \\
\hline \multirow{2}{*}{$\begin{array}{l}\text { A } \pm \text { Ambiguities: clarified or con- } \\
\text { fused }\end{array}$} & $\mathrm{AC}+\mathrm{Clear}$, unambiguous statements \\
\hline & A + Discuss ambiguities to clear them up \\
\hline \multirow[t]{2}{*}{$\mathrm{L} \pm$ Linking ideas, interpretation } & $\mathrm{L}+$ Linking facts, ideas and notions \\
\hline & $\begin{array}{l}\mathrm{L}+\text { Generating new data from } \\
\text { information collected }\end{array}$ \\
\hline \multirow[t]{3}{*}{$\mathrm{J} \pm$ Justification } & $\mathrm{JP}+$ Providing proof or examples \\
\hline & JS + Justifying solutions or judgments \\
\hline & $\begin{array}{l}\text { JS+ Setting out advantages and } \\
\text { disadvantages of situation or solution }\end{array}$ \\
\hline \multirow[t]{2}{*}{$\mathrm{C} \pm$ Critical assessment } & $\begin{array}{l}\mathrm{C}+\text { Critical assessment/evaluation of own } \\
\text { or others' contributions. }\end{array}$ \\
\hline & $\mathrm{CT}+$ Tutor prompts for critical evaluation \\
\hline \multirow[t]{2}{*}{$\mathrm{P} \pm$ Practical utility (grounding) } & $\begin{array}{l}\mathrm{P}+\text { relate possible solutions to } \\
\text { familiar situations }\end{array}$ \\
\hline & $\mathrm{P}+$ discuss practical utility of new ideas \\
\hline $\begin{array}{l}\mathrm{W} \pm \text { Width of understanding } \\
\text { (complete picture) }\end{array}$ & $\begin{array}{l}\mathrm{W}+\text { Widen discussion (problem within a } \\
\text { larger perspective. Intervention strategies } \\
\text { within a wider framework.) }\end{array}$ \\
\hline
\end{tabular}




\section{Appendix B. Indicators of Social Presence}

\begin{tabular}{|c|c|c|c|}
\hline Category & Indicators & Definition & Example \\
\hline \multirow[t]{3}{*}{ Affective } & $\begin{array}{l}\text { Expression of } \\
\text { emotions }\end{array}$ & $\begin{array}{l}\text { Conventional expressions of emo- } \\
\text { tion, or unconventional expres- } \\
\text { sions of emotion, includes repeti- } \\
\text { tious punctuation, conspicuous } \\
\text { capitalization, emoticons. }\end{array}$ & $\begin{array}{l}\text { "I just can't stand it when ...!!!!" "AN- } \\
\text { YBODY OUT THERE!" }\end{array}$ \\
\hline & Use of humor & $\begin{array}{l}\text { Teasing, cajoling, irony, under- } \\
\text { statements, sarcasm. }\end{array}$ & $\begin{array}{l}\text { "The banana crop in Edmonton is look- } \\
\text { ing good this year" }\end{array}$ \\
\hline & Self-disclosure & $\begin{array}{l}\text { Presents details of life outside of } \\
\text { class, or expresses vulnerability. }\end{array}$ & $\begin{array}{l}\text { "Where I work, this is what we do ..." } \\
\text { "I just don't understand this question" }\end{array}$ \\
\hline \multirow[t]{6}{*}{ Interactive } & $\begin{array}{l}\text { Continuing a } \\
\text { thread }\end{array}$ & $\begin{array}{l}\text { Using reply feature, rather than } \\
\text { starting a new thread. }\end{array}$ & $\begin{array}{l}\text { Software dependent, e.g., "Subject: } \\
\text { Re" or "Branch from" }\end{array}$ \\
\hline & $\begin{array}{l}\text { Quoting from } \\
\text { others' messages }\end{array}$ & $\begin{array}{l}\text { Using software features to quote } \\
\text { others entire message or cutting } \\
\text { and pasting selections of others' } \\
\text { messages. }\end{array}$ & $\begin{array}{l}\text { Software dependent, e.g., "Martha } \\
\text { writes:" or text prefaced by less-than } \\
\text { symbol <. }\end{array}$ \\
\hline & $\begin{array}{l}\text { Referring explic- } \\
\text { itly to others' } \\
\text { messages }\end{array}$ & $\begin{array}{l}\text { Direct references to contents of } \\
\text { others' posts. }\end{array}$ & $\begin{array}{l}\text { "In your message, you talked about } \\
\text { Moore's distinction between ..." }\end{array}$ \\
\hline & Asking questions & $\begin{array}{l}\text { Students ask questions of other } \\
\text { students or the moderator. }\end{array}$ & $\begin{array}{l}\text { "Anyone else had experience with } \\
\text { WEBCT?" }\end{array}$ \\
\hline & $\begin{array}{l}\text { Complimenting, } \\
\text { expressing ap- } \\
\text { preciation }\end{array}$ & $\begin{array}{l}\text { Complimenting others or contents } \\
\text { of others' messages. }\end{array}$ & $\begin{array}{l}\text { "I really like your interpretation of the } \\
\text { reading" }\end{array}$ \\
\hline & $\begin{array}{l}\text { Expressing } \\
\text { agreement }\end{array}$ & $\begin{array}{l}\text { Expressing agreement with others } \\
\text { or content of others' messages. }\end{array}$ & $\begin{array}{l}\text { "I was thinking the same thing. You } \\
\text { really hit the nail on the head." }\end{array}$ \\
\hline \multirow[t]{3}{*}{ Cohesive } & Vocatives & $\begin{array}{l}\text { Referring to group members by } \\
\text { name }\end{array}$ & "I think John made a good point." \\
\hline & $\begin{array}{l}\text { Inclusive pro- } \\
\text { nouns }\end{array}$ & $\begin{array}{l}\text { Addresses the group as, "us, we, } \\
\text { our". }\end{array}$ & $\begin{array}{l}\text { "Our textbook refers to..."'” think we } \\
\text { veered off track ..." }\end{array}$ \\
\hline & $\begin{array}{l}\text { Phatics, saluta- } \\
\text { tions }\end{array}$ & $\begin{array}{l}\text { Communication that serves a } \\
\text { purely social function; greetings, } \\
\text { closures. }\end{array}$ & $\begin{array}{l}\text { "Hi all" "That's it for now" "We're } \\
\text { having the most beautiful weather } \\
\text { here" }\end{array}$ \\
\hline
\end{tabular}

Rourke et al. (1999) pg. 61 


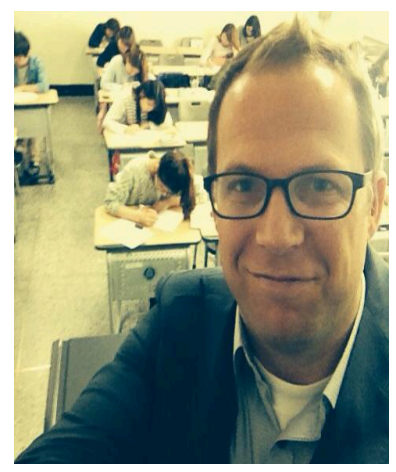

\section{Biographies}

Jamie Costley is a visiting professor in the Department of English Education at Kongju National University in South Korea, where he also earned his $\mathrm{PhD}$ in Instructional Design. Dr. Costley has been involved in teaching students in blended learning situations and researching effective online instructional strategies since 2010. His main area of research is the impact of task or learning environment design on studentto-student interaction. Dr. Costley is currently involved in research into improving instruction in online classes in South Korea, and welcomes contact on this topic.

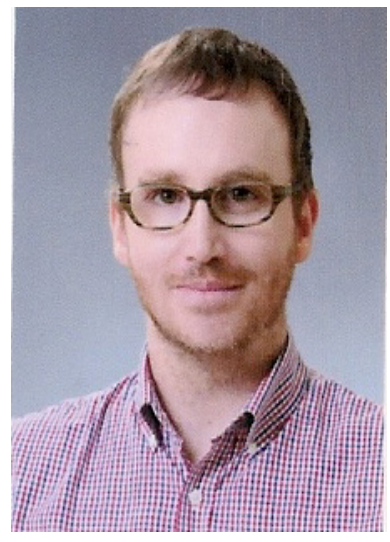

Christopher Lange is a visiting professor in the Liberal Arts department at Joongbu University in South Korea. He has collaboratively published papers on group work and e-learning environments. His current research interests are effects of interaction within online learning environments. Furthermore, he is interested in investigating ways of improving online instruction, design, and delivery to better address the needs of e-learning students. He has a Master's of Education degree from Kongju National University in South Korea, and is currently enrolled in the $\mathrm{PhD}$ program there. 